\title{
Prior Intra-operative Hypotension is not a Risk Factor for Development of Alzheimer's Disease
}

\author{
N.I. Bohnen, E.F.M. Wijdicks, E. Kokmen, M.A. Warner and L.T. Kurland
}

\begin{abstract}
Objective: A retrospective, population-based, case-control study was carried out to evaluate episodes of prior intra-operative hypotension as a potential risk factor for Alzheimer's disease (AD). Methods: Patients were all incident cases of AD from 1975-1984 who resided for 40 years or more in Olmsted County prior to their onset of dementia $(\mathrm{N}=252)$. One age and gender-matched control for each case was selected from all registrations for care at Mayo Clinic during the year of onset in the incident case. Each case and control group had 252 individuals. Results: Of these, 27 cases and 32 controls had at least one ten minute or longer episode of intra-operative hypotension of a systolic blood pressure of less than $90 \mathrm{~mm} \mathrm{Hg}$ prior to the year of onset of dementia in the matched AD patient. We did not find a significantly increased risk of $A D$ for hypotensive episodes of less than 75 or $90 \mathrm{~mm} \mathrm{Hg}$. Conclusions: It is unlikely that intra-operative hypotensive events of this degree increase the risk of $\mathrm{AD}$.
\end{abstract}

RÉSUMÉ: Une hypotension peropératoire antérieure n'est pas un facteur de risque de la maladie d'Alzheimer. But: Nous avons effectué une étude cas-témoin rétrospective, de population, pour évaluer les épisodes antérieurs d'hypotension peropératoire comme facteur de risque potentiel de la maladie d'Alzheimer (MA). Méthodes: Tous les patients étaient des cas incidents de MA de 1975 à 1984, habitant depuis 40 ans ou plus dans le comté d'Olmsted avant le début de leur démence $(\mathrm{N}=252)$. Nous avons choisi un témoin apparié pour l'âge et le sexe pour chaque cas à partir des registres de soins de la Clinique Mayo pendant l'année de début de la MA chez les cas incidents. Les groupes cas et témoins étaient composés de 252 personnes. Résultats: 27 cas et 32 témoins avaient subi au moins un épisode de dix minutes ou plus d'hypotension peropératoire avec une pression systolique de moins de $90 \mathrm{~mm} \mathrm{Hg}$ avant l'année de début de la démence chez le patient MA qui lui était apparié. Nous n'avons pas observé une augmentation significative du risque de MA associée à des épisodes d'hypotension de moins de 75 ou $90 \mathrm{~mm} \mathrm{Hg}$. Conclusion: Il est peu probable que l'hypotension peropératoire de ce niveau augmente le risque de MA.

Can. J. Neurol. Sci. 1996; 23: 57-58

General anesthetics have been associated with short-term deterioration of mental function and long-term subtle cognitive effects in post-operative patients. Most causes of long-term overt mental deterioration after surgery and anesthesia are likely explained by peri-operative complications rather than residual effects of anesthetic agents. ' Although prior exposure to general anesthesia has not been associated with an increased risk of Alzheimer's disease, early and midlife exposure to anesthetic agents has been associated with development of the disease at an earlier age. ${ }^{2}$

Are episodes of peri-operative hypotension associated with cerebral hypoperfusion, neuronal damage, and increased risk of developing $A D$ ? Increased neuronal loss is seen in the hippocampus of patients with $\mathrm{AD}$, and the pyramidal cells of the hippocampus are very susceptible to hypoxic cell damage. ${ }^{3}$ To resolve this question, we undertook the present study to determine if prior events of intra-operative hypotension are associated with subsequent development of $\mathrm{AD}$. Incident cases of $\mathrm{AD}$ from 1975-1984 in the Olmsted County, Minnesota population that had experienced one or more intra-operative hypotensive events prior to their year of $A D$ diagnosis were compared with controls matched for age, gender, and Mayo Clinic registration number in a population-based, case-control study of AD.

\section{Patients and Methods}

Residents who developed AD between January 1, 1975 and December 31, 1984 in Olmsted County, Minnesota, were identified through a review of medical records and health care correspondence. ${ }^{4}$ In brief, complete health care records of all

From the Departments of Neurology (N.I.B., E.F.M.W., E.K.), Anesthesiology (M.A.W.), and Health Sciences Research, Section of Clinical Epidemiology (N.I.B and L.T.K.), Mayo Clinic/Mayo Foundation, Rochester, Minnesota.

RECEIVED MAY 11, 1995. ACCEPTED IN FINAL FORM SEPTEMBER 28. 1995.

Reprint requests to: Dr. N. Bohnen, Department of Neurology, Mayo Clinic, 200 First Street Southwest, Rochester, Minnesota 55905, USA. 
Olmsted County residents with any diagnosis conceivably associated with dementia were reviewed. Dementia and AD was diagnosed after exhaustive review of all available health care information, including death certificates, and, when available, autopsy reports. Preselected specific criteria were used for diagnosis of dementia and AD. ${ }^{4}$ Based on this review, a year of onset of progressively dementing symptoms (index year) was assigned to each case. Residents were excluded from the study if they had undergone neurosurgery, presented with an immediate onset of dementia after surgery, or had lived less than 40 years in Olmsted County prior to the onset of dementia. Overall, 431 residents met these criteria for Alzheimer's disease and had their onset of disease between 1975 through 1984. Of these 431 residents with AD, 252 had resided in Olmsted County for 40 or more years.

\section{Selection of Controls}

Age and gender-matched controls for each AD case were selected from all Olmsted County residents who received regular medical care at Mayo Clinic during the index year of the matched-AD patient. These controls had to meet the selection criteria of a minimum of 40-year residency in Olmsted County, Minnesota. In addition, controls were excluded if they had developed $A D$ after the index year. Thus, controls were similar to patients except that they did not have dementia.

\section{Data Collection and Statistical Analysis}

General medical data were abstracted using precoded forms. Demographic information included gender, height and weight, and date of birth. Mayo Clinic records contain continuously updated history sheets that list previous surgeries and a complete medical history. Surgical and anesthetic records dating back to the beginning of this century were available for review. Anesthetic records contained well-documented charts of intraoperative blood pressure levels. Blood pressure levels were measured in 5 minute intervals. Data were abstracted for episodes of intra-operative systolic hypotension of less than 75 and $90 \mathrm{~mm}$ $\mathrm{Hg}$ lasting more than 10 minutes. Odds ratios were calculated using the SAS procedure FREQ. ${ }^{5}$ Probabilities less than 0.05 were considered significant.

\section{RESULTS}

There were 252 cases, 205 were females and 47 were males. Twenty-seven patients and 32 controls had a least one ten minute or longer episode of intra-operative hypotension of less than $90 \mathrm{~mm} \mathrm{Hg}$ prior to the year of onset of dementia in the matched AD patient (O.R. $=0.83 ; 95 \%$ C.I., 0.48 - 1.43; Table). Two cases and two controls had a prolonged episode of systolic hypotension of less than $75 \mathrm{~mm} \mathrm{Hg}$. The odds ratio for this match was 1.004 (95\% C.I., 0.14 - 7.19) (Table).

\section{Discussion}

The present study analyzed episodes of intra-operative systolic hypotension prior to the age of onset of dementia in AD cases and the corresponding age in controls. This case-control study suggests that a prior episode of intra-operative hypotension is not a significant risk factor for AD. Possible weaknesses of this study include the number of index cases and the potential inaccuracies of intra-operative blood pressure documentation, especially at hypotensive values. Automated blood pressure readings were not available for most of the years during which patients underwent anesthesia.
Table: Odds ratios for episodes of prior intra-operative hypotension lasting ten minutes or more among Alzheimer's disease cases and controls.

A. Episodes of systolic hypotension $<75 \mathrm{~mm} \mathrm{Hg}$

\begin{tabular}{llll} 
& Yes & No & Total \\
\hline Case & 2 & 250 & 252 \\
Control & 2 & 250 & 252 \\
Total & 4 & 500 & 504 \\
\hline Odds ratio & 1.004 (95\% C.I., $0.14-7.18)$ \\
\hline
\end{tabular}

B. Episodes of systolic hypotension $<90 \mathrm{~mm} \mathrm{Hg}$

\begin{tabular}{llll}
\hline & Yes & No & Total \\
\hline Case & 27 & 225 & 252 \\
Control & 32 & 220 & 252 \\
Total & 59 & 445 & 504 \\
\hline Odds ratio $0.83(95 \%$ C.I., $0.48-1.42)$ \\
\hline
\end{tabular}

An advantage of this study, however, was that all patients were community-identified incident cases of AD. Controls were matched by gender, age, and year of medical care. The cases were newly diagnosed; prevalent cases were not included and surgical histories did not influence selection of cases or controls. It should be noted that although the present study did not find an association between transient episodes of systemic hypotension and increased risk of Alzheimer's disease, cerebral hypoperfusion from other causes may still be a major risk factor for other types of dementia, such as vascular dementia. ${ }^{6}$ Research criteria for vascular dementia were recently outlined by an international NINDS-AIREN workshop and require that the patient is demented, that there is evidence of cerebrovascular disease demonstrated by either history, physical examination, or brain imaging, and that the two disorders are reasonably related. ${ }^{\text {? }}$

Whether hypotension from excessive bleeding or hypotension in the setting of critical illness is associated with increased risk of Alzheimer's disease has not been determined in this study.

\section{ACKNOWLEDGEMENTS}

This research was partially supported by NIH grants AG06786, NS17750, and AG08031.

\section{REFERENCES}

I. Hansen MB, Bigler DR. Changes in mental function after anesthesia and surgery. Ugeskrift für Laeger 1992; 154: 2000-2003

2. Bohnen NI, Kokmen E, Warner MA, Kurland LT. Early and midlife exposure to anesthesia and age of onset of Alzheimer's disease Int J Neurosci 1994; 77: 181-185.

3. Okazaki H. Fundamentals of Neuropathology. Second edition. New York: Igaku-Shoin, 1989: 60.

4. Kokmen E, Beard CM, Chandra $V$, et al. Clinical risk factors for Alzheimer's disease. A population-based control study. Neurology 1991; 41: 1393-1397.

5. SAS User's guide. Statistics Version 6, Fourth Edition, Volume 1 Cary: North Carolina: SAS Institute Inc, 1989

6. Cooper JK, Mungas D. Risk factor and behavioral differences between vascular and Alzheimer's dementias: the pathway to end-stage disease. J Geriatr Psychiatr Neurol 1993; 6: 29-33.

7. Román GC, Tatemichi TK, Erkinjuntti T, et al. Vascular dementia: Diagnostic criteria for research studies. Report of the NINDSAIREN international workshop. Neurology 1993; 43: 250-260. 